\title{
Corrigendum to "Effect of benzophenone on the physicochemical properties of N-CNTs synthesized from 1-ferrocenylmethyl (2-methylimidazole) catalyst" [J. Nig. Soc. Phys. Sci. 2 (2020) 205-217]
}

Ayomide Hassan Labulo, ${ }^{\mathrm{a}, *}$, Elijah Temitope Adesuji ${ }^{\mathrm{a}}$, Charles Ojiefoh Oseghale ${ }^{\mathrm{a}}$, Elias Emeka Elemike $^{\mathrm{b}}$, Adamu Usman ${ }^{\mathrm{a}}$, Akinola Kehinde Akinola ${ }^{\mathrm{c}}$, Enock Olugbenga Dare ${ }^{\mathrm{c}}$

${ }^{a}$ Department of Chemistry, Federal University of Lafia, Lafia, Nasarawa State, Nigeria

${ }^{b}$ Department of Chemistry, Federal University of Petroleum, Nigeria

${ }^{c}$ Department of Chemistry Federal University of Agriculture, Abeokuta, Ogun State, Nigeria

DOI: $10.46481 /$ jnsps.2021.213

Article History :

Received: 28 April 2021

Accepted for publication: 15 May 2021

Published: 29 May 2021

(C)2021 Journal of the Nigerian Society of Physical Sciences. All rights reserved.

Communicated by: B. J. Falaye

In the acknowledgment section of this article, the first and second sentences that read "This research was financially supported by the National Research Foundation (NRF) South Africa. We are grateful to the School of Chemistry and Physics, University of KwaZulu-Natal (UKZN) for creating a conducive research laboratory for this work" should have read "The authors acknowledge the School of Chemistry and Physics, University of KwaZulu-Natal (UKZN) for creating a conducive research laboratory for this work". In addition, the sentence that reads "Ayomide is grateful to Prof. Vincent Nyamori, Prof. Bernand Omondi, and Mrs. Rashidat Labulo for proofreading this manuscript" should have read "Ayomide is grateful to Mrs. Rashidat Labulo for proofreading this manuscript".

\footnotetext{
${ }^{*}$ Corresponding author tel. no: +2348062295936

Email address: labulo@yahoo. com (Ayomide Hassan Labulo ) DOI of the original article: 10.46481 jnsps.2020.105
} 